\title{
Oitenta pretos africanos, novos, em um coió, debaixo do sal: Tráfico internacional de africanos escravizados (Angola - Rio de Janeiro - Brasil meridional, 1836)
}

\author{
Eighty Young Black Africans in a coió under the salt: \\ international trafficking in enslaved Africans (Angola-Rio de \\ Janeiro - southern Brazil, 1836)
}

Paulo Roberto Staudt Moreira

Universidade do Vale do Rio dos Sinos - Unisinos

DOI: https://doi.org/10.25032/crh.v5i9.5

Recibido: $11 / 10 / 2019$

Aceptado: 25/11/2019

Resumo: Em janeiro de 1836 adentrou o porto de São José do Norte, no Brasil meridional, o patacho Dois Irmãos, vindo do Rio de Janeiro. Ao fazer a visita rotineira da embarcação, a guarda daquela barra encontrou a bordo, além da tripulação (de 9 pessoas livres e um preto ladino) e um passageiro português, 80 pretos africanos novos escondidos em um coió, debaixo da carga de sal. A carga ilegal, tendo em vista a lei de 07.11.1831, vinha do Rio de Janeiro e tinha sido colocada a bordo ao pé das Ilhas das Cagarras e Redonda. Os "43 pretos africanos e 37 pretas ditas" foram embarcadas no litoral de Angola e trazidas ao Rio de Janeiro, onde após um ano foram reconduzidos para o mercado escravista meridional. $\mathrm{O}$ sal e os africanos ilegalmente escravizados, provavelmente seriam consumidos pela economia charqueadora local, apesar daquela embarcação já ter se envolvido em contrabandos com o Uruguai. O artigo investigará, a partir do cruzamento de um documento judicial com outras fontes primárias, as ligações do tráfico internacional transatlântico com o abastecimento ilegal de escravos no Brasil meridional, além da relação da justiça com esse comércio ilegal.

Palavras-chave: escravidão, tráfico internacional de escravos, Angola.

Abstract: In January 1836 entered the port of São José do Norte, in southern Brazil, the patacho Dois Irmãos, coming from Rio de Janeiro. On a routine visit to the boat, 
the guard of that bar found on board, in addition to the crew (9 free people and one rogue black) and a Portuguese passenger, 80 young African blacks hidden in a "coió" under the salt load. The illegal cargo, in view of the law of 11.07.1831, came from Rio de Janeiro and had been placed aboard at the foot of the Cagarras and Redonda Islands. The " 43 African blacks and 37 so-called blacks" were shipped off the coast of Angola and brought to Rio de Janeiro, where after a year they were returned to the southern slave market. Salt and illegally enslaved Africans would likely be consumed by the local charcoal economy, although that vessel had already been involved in smuggling with Uruguay. From the intersection of a court document with other primary sources, the article will investigate the links of transatlantic international trafficking with the illegal supply of slaves in southern Brazil, and the relationship of justice to this illegal trade.

Keywords: slavery, international slave trade, Angola.

Segundo Herbert Klein (2004, p. 183), "hoje acredita-se que a campanha para abolir o tráfico negreiro no Atlântico, que começou no último quarto do século XVIII, foi o primeiro movimento pacífico de massa com base nos tipos modernos de propaganda política na história inglesa". Em 23 de novembro de 1826 o Brasil e a Inglaterra assinaram o Tratado ou Convenção sobre o fim do tráfico de escravos transatlântico, acordo que foi ratificado em 13 de março de 1827 (Bethell 2002). Esse acordo obrigava os brasileiros a abandonar o tráfico internacional até março de 1830, por causa disso, em 1831 e 1832, foram promulgadas legislações para deter este comércio, sem no entanto conseguir sufocar o enorme fluxo transatlântico clandestino. Tendo em vista o caráter clandestino deste comércio posterior a lei antitráfico de 1831, existem concretos motivos para considera-lo de difícil pesquisa e quantificação, afinal: "É correto afirmar que só temos acesso ao ato do contrabando quando o empreendimento fracassou" (Thompson Flores 2007 24) Assim, usaremos como mote principal deste artigo um processo judiciário que versa sobre um desembarque ilegal de africanos escravizados, ocorrido no porto da Vila de São José do Norte, em 1836, na 
província do Rio Grande do Sul, espaço mais meridional do Império do Brasil, fronteiriço a região platina. ${ }^{1}$

Em janeiro de 1836 adentrou o porto de São José do Norte, o patacho Dois Irmãos, vindo do Rio de Janeiro. Ao fazer a visita rotineira da embarcação, a guarda daquela barra encontrou a bordo, além da tripulação (de 9 pessoas livres e um preto ladino) e um passageiro português, 80 pretos africanos novos escondidos em um “coió", debaixo da carga de sal. A carga ilegal, tendo em vista a lei de 07.11.1831, vinha do Rio de Janeiro e tinha sido colocada a bordo ao pé das Ilhas das Cagarras e Redonda. Os "43 pretos africanos e 37 pretas ditas" foram embarcadas no litoral de Angola e trazidas ao Rio de Janeiro, onde após um ano foram reconduzidos para o mercado escravista meridional. $\mathrm{O}$ sal e os africanos ilegalmente escravizados, provavelmente seriam consumidos pela economia charqueadora local, apesar daquela embarcação já ter se envolvido em contrabandos com o Uruguai. O artigo investigará, a partir do cruzamento de um documento judicial com outras fontes primárias, as ligações do tráfico internacional transatlântico com o abastecimento ilegal de escravos no Brasil meridional, além da relação da justiça com esse comércio ilegal.

\section{O nefando contrabando de carne humana de 1836}

Quando a freguesia de São José do Norte foi criada, em 1820, ela estava inserida na circunscrição da vila de Rio Grande. Rio Grande foi a primeira vila criada na Capitania de Rio Grande de São Pedro, em 1747, instalada em 1751. Segundo Helen Osório (2007, p. 55), a fronteira meridional do império português sempre foi “imprecisa, móvel, provisória e permeável, verificando vários tipos de trocas e circulação de pessoas. A deserção dos exércitos, o contrabando de gado e a apropriação de terras". O avanço em direção ao extremo meridional envolvia, em grande parte, uma pretensão das elites portuguesas em se imiscuir na região platina e tem como um de seus momentos basilares a fundação da Colônia de Sacramento, vizinha a Buenos Aires, em 1680 (Kuhn \& Comissoli 2013). Desde esses primórdios da ocupação do

\footnotetext{
${ }^{1} \mathrm{~A}$ raridade deste documento não pressupõe que várias pesquisas já tenham esmiuçado o tráfico ilegal por fontes diversas como, por exemplo o historiador Marcus Carvalho (2009, 2012, 2014).
} 
território meridional da América portuguesa, o comércio de escravizados constituiu parte substancial das transações (Kuhn 2012, Studer 1984).

O decreto de 25 de outubro de 1831 emancipou de Rio Grande a vila de São José do Norte, espaço que, entretanto, persistiu tendo fortes relações com aquele porto atlântico. O historiador Moacyr Flores investigou o contrabando de escravos, acessando como fonte privilegiada as denúncias veiculadas no jornal O Noticiador, impresso na vila de Rio Grande, entre 1832 e 1835, propriedade de Francisco Xavier Ferreira (1776-1838):

[...] farmacêutico, maçom, liberal moderado e monarquista, deputado provincial, secretário e depois presidente da Sociedade Defensora da Liberdade e Independência Nacional e presidente da Sociedade Beneficência que mantinha o Hospital. Era dono da tipografia e de livraria. Mantinha uma biblioteca aberta ao público, com empréstimo de livros. (Flores 2013 7)

Francisco Xavier Ferreira pressionou as autoridades para o efetivo cumprimento da lei de 1831, chamando aquelas atividades ilegais, e que contavam com a conivência de juízes, funcionários da Alfândega e padres, de nefando contrabando de carne humana. Ele apoiou a deflagração da guerra civil de 1835 e foi preso, sendo enviado para o Rio de Janeiro, onde morreu encarcerado. Ferreira não era, entretanto, abolicionista e seu jornal persistiu publicando anúncios de compra e venda de escravizados e comunicações da entrada de embarcações no porto de Rio Grande com cativos.

Em 18 de dezembro de 1833, o jornal O Noticiador, em seu número 194, comunica que a galera portuguesa Maria da Glória trouxera de Angola 423 escravizados e ao se dirigir ao litoral uruguaio, foi apreendida pelo brigue de guerra inglês Snake, sendo o navio e a sua carga trazidos para o porto de Rio Grande. Dizia O Noticiador que era o dono do navio o português Anastácio José Ribeiro, "Continuam nossos males a dimanar de portugueses, que vem violar nossas leis e costumes". Segundo Flores, uma das estratégias dos contrabandistas era:

Os contrabandistas despachavam os navios com destino de Montevidéu e de Buenos Aires. Quando a embarcação chegava ao largo da barra de Rio Grande, o mestre ordenava que jogassem fora a água e mantimentos, assim as autoridades da Alfândega de São José do Norte eram obrigadas a socorrê-la, permitindo sua entrada no porto de Rio Grande. 
Transferiam os escravos para a escuna de Registro, onde permaneciam sem água e sem mantimentos, precisando ser socorridos (Flores 2013 25).

Desde 1828 a banda Oriental do Uruguai era um estado independente. Em 18 de julho de 1830 foi jurada uma nova constituição e criado o Estado Oriental do Uruguai, dividido em nove departamentos (Maiztegui 2010 221). A tranquilidade durou pouco na Banda Oriental, com revoltas estourando em 1832 e 1834. Em $1^{\circ}$ de março de 1835, assumia a presidência da república, por unanimidade, "sin votos en contra ni abstenciones", o general Manuel Oribe. Propugnada no programa revolucionário pela independência, em 1825, a Ley de Libertad de Vientres fez parte do texto constitucional de 1830 , certamente fruto de uma barganha com a população negra oriental, fundamental nos esforços de autonomização frente ao império brasileiro (Andrews 2010 54). No Uruguai, a relativa paz que se estabeleceu no primeiro decênio da independência, estimulou um crescimento económico no entorno de Montevideu, estimulado pelo completo estancieiro-saladeril: "La reactivación económica devino en una mayor demanda de mano de obra. La incorporación de trabajadores forzados no sólo promovió la introducción de africanos, sino el arribo de colonos españoles contratados y el empleo como sirvientes de algunos charrúas capturados" (Borucki, Chagas, Stalla 2004 19).

Apesar do decreto que defendia que, a partir de 1832, os escravos entrados no Uruguai seriam libertados, a necessidade premente de mão-de-obra fez com que o governo continuasse permitindo e patrocinando a entrada de colonos africanos (Borucki 2009). A pouca ou nula aplicação do preceito constitucional e do decreto de 1832, fica evidenciado na aprovação da lei de 14 de junho de 1837, que fazendo vistas grossas aos anos de intenso tráfico ilegal, proclamava: "Artigo $1^{\circ}$. Los negros que sean introducidos en la Republica desde la publicación de esta ley, bajo cualquier denominación que sea son libres de hecho y derecho". (Isola 1975 313-316) Ou seja, grassava na sociedade uruguaia, na década de 30 do século XIX, uma sociedade ainda fortemente escravista e carente de mão-de-obra. (Borucki, Chagas, Stalla 2004 28) Destaque-se que esta sociedade uruguaia, sedenta de braços escravizados, tinha no Brasil um fornecedor ávido para manter os senhores orientais satisfeitos².

${ }^{2}$ Lembrando que o norte do Uruguai possuía inúmeros proprietários sul-rio-grandense: (LIMA, 2016 ; Souza \& Prado 2004; Zabiela, 2002). 
Comentando a manutenção da proibição de entrada de escravizados no território oriental, José Rodríguez (2005 259) assevera:

Sin embargo, a la sombra de esta prohibición, continuó igualmente la trata de esclavos en forma clandestina, y raro era el buque procedente del Brasil que no descargara a cientos de aquellos infelices bajo la clasificación laboral de sirvientes, peones o criados de los propios encargados de su tráfico. Prueba de ello es que años después, ya en enero de 1835, continuarían arribando más barcos negreros, tales como el bergantín Triunfante y la goleta Esperanza Oriental, cuya tripulación desembarco la cantidad de 350 "colonos", según el calificativo que se les asignó. Sin embargo, las pésimas condiciones con que eran alojados a bordo por los traficantes, no pasaban desapercibidas para la Prensa de la época, y los distintos medios son más que elocuentes en tal sentido, al hacer referencia al episodio: "venian a bordo atados de dos a dos y de tres en tres, con fuertes cadenas que oprimían los pescuezos. Al ser desembarcados en el Buceo, murieron ahogados sesenta y tantos de esos infelices, debido a un temporal que los sorprendió en los botes".

Voltando ao caso brasileiro de 1836, outros casos existiram envolvendo acontecimentos reais ou suspeitos de desembarque clandestino de pretos novos no pós-1831. Mas o desembarque de 1836 gerou um documento judicial sucinto, porém permeado de pistas sobre o tráfico transatlântico ilegal e o envolvimento das autoridades nessas transações. 3

O patacho Dois Irmãos entrou na barra e porto de São José do Norte na noite do dia 24 de janeiro de 1836, vindo do Rio de Janeiro. Logo na entrada da barra, ele foi interceptado pela escuna de guerra Vigilante, comandada pelo $2^{\circ}$ tenente da marinha Manoel Maria Ricaldes Júnior. Feita a vistoria da embarcação, foram encontrados em um "coió", localizado debaixo da carga de sal que transportava, 80 africanos novos, os quais não possuíam qualquer guia, despacho ou passaporte e, portanto, configuravam uma transgressão ao fim do tráfico determinado em 1831. Popularmente, a palavra coió se refere a um "esconderijo, abrigo de malfeitores ou de gente suspeita, valhacouto" (Lello Universal Vol. 1 591), mas, nesse caso, tratava-se de um compartimento construído especialmente para esconder das autoridades esses pretos novos, usado apenas no momento da entrada na barra e aproximação do porto. Ou seja, deveria ser

\footnotetext{
3 Autos crimes pela importação de africanos novos - Arquivo Público do Estado do RS, Tribunal do Júri da Vila de São José do Norte, Comarca de Rio Grande, 1838, $\mathrm{n}^{\circ}$ 10. Agradeço ao historiador Rodrigo de Azevedo Weimer a indicação deste documento. Beatriz Mamigonian (2017, p. 574) e Vinicius Oliveira (2013, p. 84) citam o caso que trataremos a seguir, mas mencionando-o pela data do julgamento (1838) e não do desembarque efetivo (1836).
} 
um espaço de dimensões reduzidas, sem circulação de ar e carente da mínima higiene, onde não se cogitaria alocar seres humanos escravizados durante um largo período, já que a mortalidade se elevaria além do normal. O uso desta denominação indica a certeza dos envolvidos da ilegalidade das atividades que estavam praticando.

O patacho Dois Irmãos, com sua carga nefanda, foi conduzido ao porto, ficando sob a vigilância do Brigue Barca de Guerra 7 de Setembro. Na manhã do dia seguinte, o $2^{\circ}$ tenente da marinha Ricalde Júnior oficiou ao Juiz de Paz de São José do Norte, Joaquim José de Santana o ocorrido, o qual despachou na própria margem do ofício recebido, ordenando que fosse realizado Corpo de Delito e "auto de perguntas aos africanos, juramentando-se um intérprete". ${ }_{4}$ Logo o Presidente da Província do Rio Grande do Sul também ficou ciente do caso e pressionou o Juiz Municipal a respeito, recebendo como resposta que se procederia de acordo com os artigos $1^{\circ}, 2^{\circ}$ e $3^{\circ}$ da Lei de 07.11.1831, que declarava livres "todos os escravos, que entrarem no território ou portos do Brasil, vindos de fora”. Segundo essa lei, os importadores seriam processados por escravização ilegal de pessoas livres (artigo 179 do Código Criminal brasileiro) e seriam multados em duzentos mil réis "por cabeça de cada um dos escravos importados, além de pagarem as despesas da reexportação para qualquer parte da África". Seriam imputados como importadores: " $1^{0}$ O Comandante, mestre, ou contramestre. $2^{\mathrm{O}} \mathrm{O}$ que cientemente deu, ou recebeu o frete, ou por qualquer outro título a embarcação destinada para o comércio de escravos. $3^{\circ}$ Todos os interessados na negociação, e todos os que cientemente forneceram fundos, ou por qualquer motivo deram ajuda, a favor, auxiliando o desembarque, ou consentindo-o nas suas terras. $4^{\mathrm{o}}$ Os que cientemente comprarem, como escravos, os que são declarados livres no art. $1^{0}$; estes porém só ficam obrigados subsidiariamente ás despesas da reexportação, sujeitos, com tudo, ás outras penas”. 5

Conforme prometido, em 26.01.1836, o Juiz Municipal Santana e o seu escrivão Sebastião Borges de Oliveira confeccionaram o "Auto de Visita feita a bordo do patacho nacional Dois Irmãos”, do qual era mestre José Maria Ribas e proprietário Antônio Pereira de Azevedo, barco "vindo do Rio de Janeiro, com 10 dias de viagem". A

\footnotetext{
4 Ofícios a promotoria pública - AHRS - Justiça - Correspondência, São José do Norte, Juízo de Paz,
} 1836-1843, maço 47. Sobre a atuação dos juízes de paz, ver: Flory 1986.

5 Coleção das Leis do Império do Brasil. V. II - Arquivo Histórico do RS, Legislação, códice 049. 
tripulação daquele patacho era de 9 pessoas livres e 1 preto ladino ("como consta da Matricula"), um passageiro de nome João Moreira Lima (português), além de "43 pretos africanos e 37 pretas ditas, sem passaportes, carga, digo, todos novos, carga de Sal”. O Juiz perguntou ao contramestre a quem pertenciam aqueles pretos e aonde os tinham embarcado (já que o mestre não se achava a bordo, "por ter já desembarcado na Barra no momento da entrada"):

\begin{abstract}
Respondeu que foram recebidos fora da barra do Rio de Janeiro, ao pé das Ilhas das Cagarras, que ali atracaram 3 canoas com gente armada e a força lhe fizeram receber os ditos pretos Africanos, assim como apareceram em um Camarote os papéis tendentes ao mesmo Patacho, Passaporte, Matricula e outros mais.
\end{abstract}

Como não parece plausível acreditarmos em 80 pretos novos embarcados a força em uma embarcação e trazidos contra a vontade de sua tripulação, mestre e proprietários ao longo de um largo trajeto marítimo, podemos pensar o que foi dito acima, e será confirmado por outras testemunhas, como uma estratégia do tráfico ilegal. O arquipélago das Cagarras localiza-se em frente a praia de Ipanema, no Rio de Janeiro, e aquele local serviu perfeitamente aos contrabandistas, pois permitia que o patacho saísse legalmente do porto do Rio de Janeiro com a sua carga de sal e ali fossem embarcados os pretos novos.

Segundo Berute (2012 208), "entre os anos de 1790 e 1830, o Rio de Janeiro foi o maior porto importador de cativos africanos nas Américas. Do mesmo modo, era o principal distribuidor de cativos da colônia. Importantes mercados do centro-sul (Rio de Janeiro, Minas Gerais, São Paulo; Paraná, Santa Catarina e Rio Grande do Sul) eram abastecidos por via terrestre (tropas) ou marítima, com os escravos despachados a partir do porto carioca". No período de 1788 a 1831, excetuando alguns poucos anos em que os números eram inexpressivos (209), arrolou 3.355 remessas, somando 15.864 escravizados, despachados por 2.202 agentes. Ou seja, eram traficantes de ocasião que comercializavam os escravizados para o porto sulino, sendo que devemos ter em mente que "apesar das dificuldades de comprovação, cabe destacar que provavelmente parte deles teve o Rio Grande apenas como passagem em direção aos vizinhos da região do Rio da Prata" (211). Mesmo chamando a atenção para esta pulverização de pequenos despachos de escravizados dirigidos ao Rio Grande do Sul, Berute encontra alguns mais volumosos, mas não muitos. Dos 1.126 envios entre 1809 
e 1824, apenas 6 eram superiores a 76 escravizados e no período final da análise, 1826 a 1831, dos 1.194 envios só dois eram superiores a esse mesmo número (214).

Duas testemunhas assinaram o Auto de Visita do patacho Dois Irmãos, além do Juiz Municipal e do Escrivão. Eles talvez estivessem envolvidos na captura e, principalmente, na vigilância daquela embarcação: $01^{0}$ tenente da marinha Joaquim da Silva Medellos e o $2^{0}$ tenente Francisco Pereira Pinto. Esses dois sujeitos não prestaram depoimento, mas o primeiro deles foi relacionado pelo Presidente da Província do RS Antero Brito, em ofício dirigido ao governo imperial em 17.01.1837, como um dos indivíduos que "muito se tem distinguido, por suas ações de valor e heroísmo, nesta porfiada contenda, esperando que se digne faze-la subir a presença do Governo". Segundo essa autoridade, que era o principal representante do Império na província, $\mathrm{o} 1^{\circ}$ tenente Medellos -"é de muito valor; a ele se deve a primeira defesa da Vila do Norte, não se poupou a trabalhos, mesmo braçais, e muito encorajou os desanimados e inermes habitantes: trabalhou muito no Canal de Itapuã, e conseguiu passar algumas embarcações com incrível trabalho" ${ }^{6}$

Dois dias depois do desembarque, foi confeccionado o Auto de Corpo de Delito dos escravizados a bordo do Patacho, "indigitado de haver conduzido pretos africanos vindos depois da proibição de semelhante tráfico". Foram encontrados 80 pretos:

[...] conduzidos para esta província, que nada falam do idioma brasileiro, reconhecendo-se visivelmente serem introduzidos por contrabando, segundo as perguntas que se lhe fez por via de intérprete e respostas que eles deram. E passando o Juiz a tomar conhecimento da Nação que pertenciam pelo mesmo intérprete, que 23 eram de Nação Congo, inclusive 10 fêmeas, e todos estes de 8 a 12 anos de idade, e 18 pretas de Nação Embacá, 27 pretos da mesma Nação, sete pretas Benguela, de 8 a 12 anos, 4 pretos da mesma Nação, e uma preta de nação Cassange, de 10 anos de idade, pouco mais ou menos, disse o intérprete que eles lhe diziam que tinham embarcado em Angola para o Rio de Janeiro, onde estiveram um ano pouco mais ou menos.

Rodrigues informa que é complicado estabelecer classificações rígidas quanto aos tipos de barcos usados no tráfico transatlântico, sendo que o critério por vezes era a capacidade de carga, outras a mastreação. Rodrigues (2010 147) lista 15 "tipos de navios mencionados nos processos julgados na Comissão Mista Anglo-Brasileira

${ }^{6}$ Ofício do Presidente da Província do RS, de 17.01.1837 - Arquivo Nacional - Rio de Janeiro - Gabinete do Ministro dos Negócios da Justiça - $\mathrm{IJ}^{1} 848$. 
sediada no Rio de Janeiro" - brigues, bergantins, brigue-barca, brigues-escuna, barcas, escunas, cúter, galeota, galeras, patachos, iates, paquete, sumacas, polacas, vapor. Do total de 155 embarcações encontradas por ele, 20 são definidas como patachos, dos quais em 9 foi possível descobrir a tonelagem, com uma média de 127 toneladas, bem inferior a média das barcas e galeras, que passavam das 250 toneladas. Entretanto:

\begin{abstract}
Embora os bergantins carregassem menos escravos devido às suas limitações espaciais, eram mais velozes - ou mais veleiros, como se dizia no linguajar marítimo do século XIX. Essa característica poderia ser um dos fatores que levavam as embarcações de dois mastros (brigues, escunas, patachos, sumacas e bergantins) a estar entre os tipos prediletos para o comércio negreiro no período da repressão mais intensa promovida pelos ingleses (Rodríguez 2010 149).
\end{abstract}

Usando dados de Eltis, Boxer e Florentino, Rodrigues (2010 156) evidencia que o tempo de viagem entre Angola e o Rio de Janeiro, entre 1821 e 1843 , era de 34 a 38 dias e que essa média teria diminuído em relação ao período anterior. Na opinião de Florentino (1997 213), essa diminuição foi acarretada pela utilização de barcos menores e mais velozes "pertencentes a traficantes não especializados que buscavam lucrar com o grande aumento da demanda depois da abertura dos portos”. Nada nos habilita a pensar que o patacho Dois Irmãos tenha cruzado o Atlântico, mas as informações constantes no processo nos ajudam a pensar nos meandros do lucrativo tráfico ilegal de seres humanos.

Infelizmente, o intérprete que foi juramentado, não foi identificado no processo. Imaginamos que certamente deveria ser um africano, pelo conhecimento das línguas e dos costumes daquele continente e do tráfico transatlântico. Não sabemos em que língua ele se dirigiu aqueles 80 africanos boçais, talvez uma língua geral da região Congo-Angola ou quem sabe ele manejava vários dialetos locais. Ele indagou daqueles pretos novos, a pedido da autoridade judicial, a respeito das suas nações:

\title{
Tabela 1
}

Nações dos 80 africanos apreendidos no patacho Dois Irmãos (1836)

\begin{tabular}{|l|c|c|}
\hline Nações & Mulheres & Homens \\
\hline Congo & 10 & 13 \\
\hline Embacá & 18 & 27 \\
\hline Benguelas & 7 & 4 \\
\hline Cassange & 1 & \\
\hline Total & $36(45 \%)$ & $44(55 \%)$ \\
\hline
\end{tabular}


Os dados da tabela acima com relação ao sexo indica relativo equilíbrio, com $45 \%$ de mulheres e $55 \%$ de homens. A maneira como as idades estão informadas pode nos induzir a erro, mas supomos que esses pretos novos estivessem, em sua maioria, senão todos, entre os 8 e os 12 anos de idade, crianças chamadas naquela sociedade escravista de moleques, faixa etária em que se aprendiam os ofícios e habilidades profissionais dos plurais mundos do trabalho escravista. Se como cogitamos, o sal e os pretos novos estavam sendo dirigidos para a região charqueadora de Pelotas, eles estavam na idade perfeita para aprender os diversos ofícios requeridos pelos empresários daquelas unidades produtivas saladeris ou quem sabe serem introduzidos na lida com os animais vacuns (ver: Berute 2006, Vargas 2013, Gutiérrez 2001, Pinto 2012, Al-Alam 2007).

Todas definições de nações acima se referem a África Central Atlântica e tem sido citadas em várias fontes documentais. O curioso é que essa linguagem do tráfico tenha saído da boca de africanos recém chegados, apesar que, conforme as testemunhas, eles já se encontravam no Brasil há um ano, mais ou menos. O fato de nada falarem do idioma brasileiro mostra como a permanência no Rio de Janeiro, não teve a intenção de fazê-los passar por um aprendizado que os ladinizasse, mas provavelmente ficaram ali aguardando o momento e o meio adequado para serem distribuídos pelos centros escravistas do império e talvez dos países do Prata. A linguagem do tráfico eles podem ter aprendido no próprio litoral africano, onde devem ter permanecido por algum tempo, aguardando a nau que os faria atravessar o Atlântico. Segundo Gomes, Soares, Farias (2005 25):

[...] sabemos muito pouco sobre o tráfico ilegal, justamente no segundo quartel do século XIX, quando o Rio de Janeiro recebeu dezenas de milhares de africanos e novas áreas do tráfico estavam sendo abertas, enquanto outras estavam definitivamente fechadas. Destacamos as áreas renovadas do norte do Congo e, sobretudo, as regiões ao sul de Angola. Outros grupos de procedência africanos caíam - por vezes menos sistematicamente - nas malhas do comércio negreiro transatlântico. Isso ajudaria a pensar impactos demográficos e transétnicos redefinidos na diáspora.7

\footnotetext{
7 Sobre o tráfico escravista em Angola, ver: Alencastro (2000), Ferreira (2001), Acioli \& Menz (2008).
} 
O Juiz de Paz Santana manda então que os "pretos africanos apreendidos" fossem depositados e em 5 de fevereiro de 1836 inicia um sumário, com a coleta de depoimentos, indicando como os introdutores dos pretos novos o proprietário do patacho Dois Irmãos e o seu mestre. O primeiro a depor foi o responsável pela apreensão, o $2^{0}$ tenente da marinha imperial Ricalde Júnior (branco, solteiro, natural desta província, 23 anos), que relatou o que parece ter sido uma inspeção de rotina, quando "se encontraram no Porão, em uma cavidade debaixo do sal, oitenta Pretos Africanos novos, que vinham na mesma embarcação, sem despacho, em razão do que lhe lançou a bordo uma escolta de cinco soldados, e um marinheiro" e "diz mais a testemunha que na ocasião da mencionada visita, já se não achavam a bordo do dito patacho o Mestre e o dono, e lhe constou terem desembarcado na Barra, no momento da entrada”. Outra testemunha foi o índio João Bernardo (solteiro, natural de São João da Parnaíba / Piauí, com 20 anos de idade e vivia de ser marítimo), que acompanhou a visita no patacho Dois irmãos, no qual foi encontrado no porão, "por baixo do sal, em um coió, oitenta Pretos Africanos, Novos, e logo o seu Comandante ali pusera uma escolta". Disse mais "que o Coió onde os ditos pretos Africanos vinham por debaixo do Sal era da banda da ré". Depois depôs o contramestre do patacho apreendido, o português Julião Ferreira, "solto, livre, sem constrangimento" (súdito brasileiro, solteiro, 26 anos, vive da arte do mar, morador a bordo do Patacho Dois Irmãos). Ele garantiu não saber a quem pertenciam os ditos pretos Africanos e que quanto ao coió, o compartimento fora feito no Rio de Janeiro, antes de saírem da barra, "feito a meia nau, na [supoltura] do dito Patacho".

Outro português fazia parte da tripulação daquele patacho. Tratava-se do marinheiro Manoel Soares da Costa Neves (casado, 28 anos de idade). Sendo the perguntado a quem pertenciam os ditos pretos africanos, relatou que "que o dono do Patacho Antônio Pereira de Azevedo foi que tomou conta dos ditos pretos Africanos, quando embarcaram para Bordo do Patacho". Manoel, que dizia viver da arte do mar estava convicto de que os pretos novos eram do dono do patacho, "pois que os tratava como seus". Informou ainda que os pretos africanos, durante a viagem do Rio de Janeiro a São José do Norte, vieram no convés, "e a entrada da Barra deste Porto é que foram metidos neste Porão, em o Coió”.

Em 18.02.1836, o Juiz de Paz Santana, considerou que os interrogatórios obrigavam a prisão e livramento dos réus Antônio Pereira de Azevedo e José Maria 
Ribas, o primeiro como proprietário do patacho Nacional Dois Irmãos e o segundo como o Mestre. De acordo com a lei de 07.11.1831 e o seu regulamento de 12.04.1832, aquele juiz ordenou que o escrivão lançasse os nomes dos acusados no livro dos réus e “passe as ordens necessárias para serem presos". O decreto de 12.04.1832 deu regulamento para a execução da lei antitráfico do ano anterior, atribuindo ao Juiz de Paz a prerrogativa de vistoriar as embarcações suspeitas, e o seu parágrafo $5^{\circ}$ determinava o depósito dos africanos novos.

O desembarque de janeiro de 1836 praticamente coincidiu com o início dos combates da guerra civil farroupilha (1835/1845). Os problemas bélicos persistiam e em 30 de abril de 1838 as tropas imperiais sofreram uma retumbante derrota na chamada batalha do Barro Vermelho, quando os farroupilhas tomaram a importante cidade de Rio Pardo. Dois meses depois, o Presidente da Província do RS cobrava do então Juiz Municipal de São José do Norte, Manoel de Sá Araújo, a reunião do júri, ao que aquela autoridade judiciária retrucou que era impossível, tendo em vista o "desastre da coluna legal" em Rio Pardo e a ameaça da cidade ser sitiada - "os cidadãos que compõem o júri estão em armas". ${ }^{8}$

Talvez não só a pressão do governo imperial e mesmo de alguns órgãos da imprensa, mas o clima de desconfiança gerado pela guerra civil farroupilha tenha "prejudicado" os contrabandistas de pretos novos. Em 22.03.1836 o Juiz Municipal de São José do Norte Joaquim da Silva Lima, comunicou ao Promotor Público que fez uma busca a bordo do patacho Aurora, pois constava que ali vinham pessoas "suspeitas", prendendo na ocasião o padre Manoel Francisco de Andrade, acusado de “conduzir correspondências dos Anarquistas". Em 19 de março do mesmo ano uma busca no brigue nacional Boa Nova encontrou, junto a cargas de sal e fazendas, 4 caixas com espadas embarcadas no Rio de Janeiro, a serem entregues em Porto Alegre a um fulano Diederich. ${ }^{9}$ Ou seja, as embarcações estavam passíveis de serem vistoriadas em busca de anarquistas farroupilhas e não necessariamente contrabandistas de pretos novos.

8 Ofício de 30.06.1838 do Juiz Municipal de São José do Norte - Arquivo Histórico do Rio Grande do Sul - Justiça, Correspondências, São José do Norte, Juízo Municipal e ou Municipal e Órfãos, 1833-1840, maço 45 .

9 Ofícios a promotoria pública - AHRS - Justiça - Correspondência, São José do Norte, Juízo de Paz, 1836-1843, maço 47. 
Finalmente, em 30.07.1838, o Juiz Municipal e de Direito interino Sá Araújo conseguiu reunir o júri no paço da Câmara Municipal e os 23 jurados, após tomarem conhecimento do processo, acharam "matéria para a acusação contra os réus José Maria Ribas e Antônio Pereira de Azevedo". O juiz então, "conformando-me com a decisão do júri”, mandou prender os réus. Já no mês seguinte, outro indivíduo assumiu o caso. O Juiz Municipal e de Direito Francisco da Costa Pinto expediu mandato de prisão em 12.11.1838 contra os réus, por crime de "importadores de escravos novos africanos". Surpreendentemente, passados dois anos do desembarque clandestino, os réus não estavam fugidos, pois, poucos dias depois, em 19.11.1838, o oficial de justiça Constantino Maria prendeu ambos na mesma vila do Norte. ${ }^{10}$ Se os réus ficaram por perto confiando na conivência da justiça e principalmente da favorável opinião comunitária livre, branda com relação ao tráfico ilegal de pretos novos, eles estavam absolutamente certos. O júri se reuniu logo em seguida, em 20.11.1838, nenhuma das testemunhas compareceu e o Promotor Público Joaquim Pires de Almeida Lopes fez então o seu libelo acusatório, acusando os réus de agirem "convencidos do dito crime, havendo procedido nele com má fé e com intenção de o praticarem, não só pela forma do embarque dos ditos Africanos e a ocultação no ato da visita do registro e sua ausência a bordo, e portanto, merecedores das penas correspondentes".

No dia seguinte, o júri reuniu-se e ouviu o depoimento dos réus. José Maria Ribas declarou ser natural desta província, ter 40 anos de idade e trabalhar como marítimo. Antônio Pereira de Azevedo informou ser português, com 31 anos de idade, solteiro e ocupar-se de negócios. Os dois disseram que sabiam a razão de estarem respondendo a júri, mas declararam que não sabiam de quem eram esses pretos novos. O juiz então indagou de que maneira podiam dizer isso, se um era o Mestre e o outro proprietário do patacho, ao que Ribas respondeu que haviam sido obrigados a aceitar o embarque dos africanos contrabandeados, no que foi apoiado por Azevedo, que acrescentou "que nesta ocasião [no litoral carioca] a embarcação estava em calmaria". O juiz perdeu a paciência e disse que "eles respondentes faltavam com a verdade, como eles não se tinham se oposto aquele ato? responderam que não o puderam repelir, pois que o poder da força a isso os obrigou". O defensor dos réus produziu "verbalmente a

10 Constantino Maria foi testemunha em um processo de 1843, onde aparece como branco, viúvo, carcereiro e oficial de justiça, com 43 anos de idade. Arquivo Público do Estado do RS - Juízo Municipal, 1843, Autos de recurso em causa crime, Recorrente: o Promotor Público da Comarca, Recorrido: Juiz Municipal. 
sua defesa" e depois foram, então, estipulados os quesitos a serem respondidos pelos jurados, mas a convicção dos juízes de fato tornou aquela sessão de deliberação rápida. Ao quesito - "Existe crime no fato ou objeto da acusação?" - responderam "pela negativa, tanto de um, como de outro réu". Assim, o desembarque dos 80 pretos novos de 1836, terminou com o juiz conformando-se com a decisão do júri, absolvendo os réus e ordenando que a municipalidade paga-se as custas.

O Mestre ou marítimo Ribas era filho de Manoel José Ferreira (natural da cidade de Braga) e Antônia Maria Ribas (natural da cidade de São Paulo). Ele casou com Lucinda Maria Ribas, filha de Antônio José de Araújo e Joaquina Maria da Silva, ambos naturais da freguesia de São Luiz de Mostardas. O casal José e Lucinda teve seis filhos e encontramos os batismos de dois deles na paróquia Nossa Senhora dos Navegantes, em São José do Norte: Belmira (nascida em 17.09.1830 e batizada em 04.11.1830), José (nascido em 14.11.1839 e batizado em 20.12.1839) e Eliseu (batizado em 26.07.1849). ${ }^{11}$ A questão dos desembarque de pretos novos de 1836/1838 não afetou a vida desse marítimo. Ele continuou tocando a sua vida nos arredores do local do desembarque, não tendo sofrido, ao que parece, qualquer estigma comunitário quanto a sua participação naquele nefando comércio. Em seu inventário post-mortem, aberto em 1877, na cidade de Pelotas, são arroladas 7 casas naquela cidade, parte de uma chácara em Cangussú e três escravizados.

O promotor público Almeida Lopes faleceu em 14 de março de $1883 .{ }^{12} \mathrm{Em}$ seu testamento, no qual registrou suas últimas vontades - "adoentado, mas em meu perfeito juízo" -, contou que nasceu em Portugal, na freguesia de São Miguel, no arcebispado de Braga, seus pais já eram defuntos (Joaquim Pires dos Santos e Isabel Antônia Lopes). Casou com Maria Luiza do Espírito Santo, com quem teve apenas um filho, que morreu maior de idade na Ilha da Madeira. Deixou 800 mil réis "aos pretos e pretas cativos de nossa casa, e livres o Sinfrônio e Adão, estes não contemplados nos 800 mil réis”. Os pretos e pretas da casa, localizada em São José do Norte, eram

\footnotetext{
${ }^{11}$ Inventário post-mortem de José Maria Ribas - Arquivo Público do Estado do Rio Grande do Sul - $1^{0}$ Cartório Civil e Crime, Pelotas, 1877, inventário nº 93.

${ }^{12}$ Inventário post-mortem de Joaquim Pires de Almeida Lopes - Arquivo Público do Estado do RS Juízo Municipal, São José do Norte, inventário no 145.
} 
quatro: o crioulo Luiz (de 31 anos), Joaquim (de nação, com 49 anos - portanto, escravizado ilegalmente), a crioula Serafina (51 anos) e a crioula Vitorina (de 27 anos).

O Juiz Sá Araújo faleceu sem testamento em 19 de abril de 1876. Era casado com Maria Ludgera de Azevedo Sá. ${ }^{13}$ Ele morava em Pelotas na ocasião de sua morte e legou um bom patrimônio a seus cinco filhos, composto de 80 reses mansas de criar, 40 ovelhas, uma chácara em frente a estrada que vai para Monte Bonito, com potreiro ao lado, objetos em prata, alguns móveis e 12 escravizados. Nenhum dos escravizados tem a idade mencionada e apenas um era descrito como africano, o carneador José, avaliado em 600 mil réis.

$\mathrm{O} 2^{\circ}$ Tenente da Marinha Ricalde Junior requereu o prêmio pela apreensão de 1836, que lhe cabia de acordo com a lei de 1831, ao que a tesouraria provincial recusou. Foi feita então uma consulta ao Imperador, respondida pelo Ministério da Justiça, o qual concordou com a decisão do órgão provincial. ${ }^{14} \mathrm{Na}$ verdade, pelo artigo $5^{\mathrm{O}}, \mathrm{o} 2^{\mathrm{O}}$ Tenente Ricalde Júnior teria direito ao prêmio, mas os artigos $6^{\circ}$ e $9^{\circ}$ especificavam que os prêmios aos denunciadores seriam descontados das multas cobradas dos contrabandistas, mas como eles foram absolvidos na sessão do júri, nada havia a pagar.

O tenente Ricalde Júnior era ele próprio coproprietário de uma embarcação. Tratava-se do patacho nacional Francina, que ele possuía em sociedade com o capitão ou mestre Francisco Lopes Guimarães. O patacho Francina naufragou em 12 de dezembro de 1847, durante uma viagem do Rio Grande ao Rio de Janeiro, próximo a Itajaí, na província de Santa Catarina. Suspeitava-se que o naufrágio fosse criminoso ("muito de propósito") e que o mestre Guimarães teria agido assim para receber o prêmio do seguro, sendo imediatamente preso por estelionato. O patacho estava avaliado em 12 contos e 400 mil réis, sendo segurado por 10 contos. ${ }^{15}$

O Presidente da Província do RS, em janeiro de 1837, enviou ao governo imperial brasileiro uma relação dos indivíduos que "muito se tem distinguido, por suas ações de valor e heroísmo nesta porfiada contenda, esperando que se digne faze-la

\footnotetext{
13 Inventário post-mortem de Manoel de Sá Araújo - Arquivo Público do Estado do RS $-1^{\mathrm{o}}$ Cartório Civil e Crime, Pelotas, 1877 , Inventário ${ }^{\circ} 94$.

14 Ofício de 18.01.1838, do Ministro da Justiça Bernardo Pereira de Vasconcelos ao Presidente da Província de São Pedro - Arquivo Histórico do RS, B.1-107.

15 Processo judicial - Arquivo Público do Estado do RS - Juízo do Civil de Porto Alegre, processo judicial de embargo $\mathrm{n}^{0} 2814,1848$.
} 
subir a presença do Governo". Nela estava o $2^{\circ}$ tenente de comissão Ricaldes, o qual "assistiu a muitos combates; já servia antes da revolta; é de valor e intrepidez: merece ser confirmado $2^{0}$ tenente". ${ }^{16}$ Segundo a sua fé-de-ofício, Manoel Maria Ricaldes Júnior deve ter se beneficiado desta boa recomendação. ${ }^{17}$ Logo depois daquele ofício de janeiro de 1837, em fevereiro do mesmo ano, ele foi promovido a efetividade do posto de $2^{\mathrm{o}}$ tenente da Armada. Antes do final da guerra civil, por decreto de 23.07.1842, foi novamente promovido, desta vez a $1^{\circ}$ Tenente, sendo reformado em 1852, quando então trabalhava na Capitania do Porto da província do RS. Ricaldes Júnior passou por várias embarcações, comandando muitas delas, mas especificamente com relação a escuna de guerra Vigilante, ele a comandou pela primeira vez de julho de 1834 a outubro de 1835 , quando passou para a escuna Pelotas. Ele voltou ao comando da escuna Vigilante em 23 de janeiro de 1836, quando então fez a apreensão dos 80 pretos novos, mas permaneceu neste posto somente até março, quando foi transferido para a canhoneira São João Brasileiro em 11 de março do mesmo ano.

Se os autos deixam transparecer certa irritação ou cansaço do juiz municipal e do promotor público com a conivência dos jurados ao desrespeito da lei antitráfico de 1831, documentos do mesmo período e local evidenciam que tais casos não foram assim tão raros. Não trataremos nesse artigo, mas pelo menos outro desembarque ocorreu neste mesmo porto, em 1834, quando 24 pretos novos foram encontrados e apreendidos no Bergantim Prazeres, que vinha da Bahia para a cidade de Pelotas. A embarcação pertencia a um dos maiores charqueadores de Pelotas, o Comendador Antônio José de Oliveira Castro.

\section{O patacho Dois Irmãos}

Em ofício de 24.03.1836, enviado ao Ministro da Justiça do Império, o Presidente da Província Araújo Ribeiro fala do reforço da guarnição de São José do Norte, vila que vivia o assédio das forças farroupilhas, com o "adjutório que recebe agora de gente que veio dessa Corte e o de 3 peças de 12 que ali mais se colocaram. A

16 Ofício de 17.01.1837 do Presidente da Província do Rio Grande do Sul ao Ministério dos Negócios da Justiça - Arquivo Nacional (Rio de Janeiro), Gabinete do Ministro, maço IJ'1848.

17 Fé-de-ofício de Manoel Maria Ricaldes Júnior -Arquivo da Marinha - Divisão de Acesso à Documentação / Diretoria do Patrimônio Histórico e Documentação da Marinha - Manoel Maria Ricalde Júnior -. 
gente que a tem em sítio não é capaz de a tomar, e se a sua Guarnição não sai para fora a afugentá-los, é por falta de Cavalaria”.18

O patacho Dois Irmãos, apreendido pela justiça imperial brasileira em janeiro daquele ano, foi usado por um tempo, como presiganga, ou seja, embarcação que servia como cadeia, ficando ancorada junto ao porto da vila de São José do Norte. Em correspondência dirigida ao Ministro da Justiça Antônio Paulino Limpo de Abreu, datada de 20.06.1836, o Presidente da Província Araújo Ribeiro dá informações a respeito. Segundo ele, quando da invasão da vila de Pelotas por insubmissos farroupilhas, a maior parte dos habitantes e das autoridades daquela localidade migraram e o Juiz de Direito mandou que os presos da cadeia local fossem remetidos para a vila do Norte em um patacho "que foi aprisionado nesta Barra com Africanos a bordo". O patacho presiganga ficou ancorado no porto dessa vila vigiado pelo Brigue Barca Sete de Setembro, mas durante um temporal ocorrido na noite de 14 para 15 de junho de 1836 , e graças a duas sentinelas coniventes, os presos se evadiram e passaram todos para as fileiras anarquistas, auxiliando no sítio que sofria a cidade.

Até pelo menos 1838 essa situação persistiu, como demonstra um processo judiciário tramitado naquele ano. Em 16.02.1838, o Presidente da Província Antônio Eliziário de Miranda e Brito mandou que fosse processado por Crime de Responsabilidade o Juiz Municipal de São José do Norte, Francisco da Costa Pinto, por ter libertado o anarquista farroupilha Antônio Furtado da Rosa, que se achava a sua ordem preso na presiganga, "surta neste porto". Alguns dias antes, o Comandante da Guarnição da cidade do Rio Grande Francisco de Castro Matutino Pitta denunciou que fora "escandalosamente" concedido Habeas Corpus a Rosa, o que não podia ter acontecido, já que ele estava envolvido em casos de insurreição e rebelião (vedado pelo artigo 342 do Código de Processo Penal do Império, aprovado em 29.11.1832). Matutino Pitta redigiu e assinou o seu ofício a bordo da presiganga pataxo Dois Irmãos, que estava, naquele momento ancorada junto ao porto da vila de Rio Grande. Ele afirmou que o Comandante da Presiganga, o $2^{\circ}$ tenente João Hipólito da Fonseca,

${ }^{18}$ Carta do Presidente da Província Araújo Ribeiro ao Ministro da Justiça, 24.03.1836 - Arquivo Nacional - Rio de Janeiro - Gabinete do Ministro - IJ1847 - Ofícios da Presidência da Província do RGS dirigidos ao Ministério dos Negócios da Justiça - 1837a 1836. 
não era "pessoa idônea para aquele emprego" e insinua que houve suborno das autoridades envolvidas ("Dizem que houve dinheiro em tal concessão"). ${ }^{19}$

A escala ou destino final em portos meridionais parece ter sido parte da rotina da embarcação Dois Irmãos. Supomos que ela estivesse ancorada no porto de Rio Grande em 1835, mesmo que fosse descrita nos documentos como sumaca e não patacho, como em $1836 .{ }^{20} \mathrm{Em}$ abril de 1835 o então mestre da sumaca Dois Irmãos, Francisco da Rocha Cruz, reclama da agressão sofrida do marinheiro português Manoel Antônio (com 30 anos de idade). Conta o mestre Cruz, que o desacordo foi referente ao pagamento de soldo e o marinheiro, além de injuriá-lo de patife, ladrão e outros termos desabonadores, deu-lhe uma bofetada e jogou-lhe algumas moedas no rosto.

Outro documento nos faz confirmar o trânsito destas embarcações pelas fronteiras platinas e, além disso, que o patacho Dois Irmãos, com a absolvição de seus envolvidos em 1838, tenha sido devolvido a seu proprietário. Em 29.01.1844, na Muito Heroica Vila do Norte, na residência do Juiz Municipal Manoel José da Silva, foi formado o auto inicial para Processo de Contrabando, no qual se processava o passageiro e fretador do Brigue Nacional Dois Irmãos, Miguel Geordano, por ter carregado de Montevidéu seis barris que foram declarados como comportando alcatrão e uma barriquinha com pregos, mas que na verdade traziam pólvora fina inglesa, "contendo 1.577 libras, na importância total de 946 mil e 200 réis". ${ }^{21}$ A suspeita, baseada em rumores, era de que a pólvora seria remetida para a campanha, onde abasteceria as tropas farroupilhas. O nome Dois Irmãos parece referir-se a embarcação que carregara os 80 africanos boçais contrabandeados em 1836, mas a sua classificação de brigue (e não patacho) pode indicar que se trata de um barco simplesmente homônimo. O termo de apreensão foi realizado em 16.01.1844, na ponte da Alfândega da Vila do Norte. O barco vinha de Buenos Aires, com escala em Montevidéu, e os gêneros, foram examinados e apreendidos pelo Feitor interino

19Processo de Crime de Responsabilidade, 1838 - Arquivo Público do Estado do Rio Grande do Sul Tribunal do Júri da Vila de São José do Norte, autor: O Promotor Público, réu: Francisco da Costa Pinto (Juiz Municipal da Vila de São José do Norte). O júri reunido em 20.07.1838 considerou o processo improcedente.

${ }^{20}$ Queixa de 08.04.1835, de Francisco Rocha da Cruz - Arquivo Histórico do Rio Grande do Sul, Fundo Justiça, Maço 91, Rio Grande, Processo 0650.

${ }^{21}$ Processo de Contrabando, 1844. Arquivo Público do Estado do Rio Grande do Sul, Porto Alegre, Juízo Municipal de São José do Norte, auto 26, caixa 791. 
Antônio Antunes da Porciúncula e enviados ao Depósito Militar da vizinha vila do Rio Grande, pois na Vila do Norte não havia local apropriado.

\section{Considerações finais}

Não sabemos o destino dos 80 pretos novos de 1836, mas supomos que tenham sido devolvidos ao Rio de Janeiro e lá tenham engrossado o número dos africanos livres. No prefácio ao livro de Beatriz Mamigonian (2017, p. 9), João José Reis alerta que a expressão africano livre foi um eufemismo jurídico, "pois se trata de expressão tipicamente ideológica, que esconde uma realidade bem diversa da enunciada”. Mas devemos salientar, que não se trataram de casos esparsos e poucos, mas de uma realidade que abarcou cerca de 11 mil africanos no Brasil. O segundo artigo da lei de 1831, especificava que o governo seria responsáveis pelos africanos apreendidos e pela sua devolução à África, entretanto, a reexportação destes africanos nunca ocorreu e era mesmo desaconselhada pelas autoridades britânicas, que temiam que os regressados fossem reescravizados (Mamigonian 2017 34, 79).

Segundo Mamigonian (98), “a distribuição dos africanos livres para o serviço, a partir de 1835, foi conduzida pelo juiz de órfãos, com a aprovação do Ministro da Justiça" (98). Analisando o destino de 955 africanos escravizados desembarcados no Brasil, de 1834 a 1838, seja em navios ou apreensões avulsas, essa historiadora (100) conclui que eles, majoritariamente, foram distribuídos a particulares (82\%), enquanto que apenas $18 \%$ foram entregues a estabelecimentos públicos. No caso das mulheres, a proporção aumenta, com 95\% sendo entregues para particulares e apenas $5 \%$ para o serviço público. Mamigonian afirma categoricamente que o aumento da população de escravizados no Rio de Janeiro, entre 1828 e 1849, de 50 para 78 mil, "se deveu especialmente à importação de africanos novos" (143).

Já com relação a carga de sal que o patacho Dois Irmãos transportava legalmente, acobertando o tráfico de africanos escravizados ilegalmente, o juiz de Paz Santana encontrou problemas em seu desembarque, pois, segundo ele, naquela vila não havia a "prática em descarregar este gênero para terra”, nem havia "armazéns a propósito para isso". Trazido para as atividades saladeris, o sal deveria ser enviado diretamente para Pelotas ou talvez para a vizinha Rio Grande, cidade onde existiam charqueadas (Scherer 2008). Justificando por essa falta de condições para o seu 
acondicionamento, o juiz lançou editais para que a carga fosse arrematada. A carga era de 1.176 alqueires de sal, avaliada em 520 réis por alqueire, totalizando 611 mil réis. Curiosamente, a quantia ficou com o próprio sujeito arrematante do sal, "por ser pessoa idônea", já que o juiz municipal alegava que não sabia o destino que deveria ter; somente em março de 1836 , o valor passou para a coletoria do Norte. ${ }^{22}$

No processo montado pela justiça em 1836, vemos que a tripulação do patacho Dois Irmãos era de 9 pessoas livres e um preto ladino, além de um passageiro, o português João Moreira Lima. Esse lusitano foi apenas citado no início dos trâmites judiciários, mas depois simplesmente sumiu dos autos, não sendo chamado para depor, apesar de viajar junto da carga humana contrabandeada e de certamente tê-los visto no convés. $\mathrm{O}$ surgimento e desaparecimento deste personagem pode ter sido fortuito, mas um documento encontrado junto à Corte de Apelação do Rio de Janeiro, nos faz supor que ele podia ser o proprietário daqueles 80 pretos novos ou talvez um agenciador da venda dos mesmos.

O litígio teve início com um requerimento do proprietário do patacho Dois Irmãos, Antônio Pereira de Azevedo ao Juiz do Cível de Rio Grande, Joaquim José da Cruz Secco, informando "que não se tendo conciliado com o seu devedor João Moreira de Lima, como mostra pelo documento junto", requeria que ele fosse citado. Azevedo alegava que conduzira, da Bahia, em setembro de 1835, cento e um sacos de farinha e um baú com sapatos "de conta do réu", pelo frete de $42 \$ 400$, cujos volumes foram despachados na Alfândega desta cidade do Rio Grande e deles tomou conta o mesmo réu, como legítimo dono. A pedido de Moreira Lima, Azevedo ainda "remeteu da cidade de Pelotas na Barca de Vapor Liberal, em janeiro de 1836, 50 caixões de velas de sebo", que foram entregues em Rio Grande a José dos Santos Mogano, pagando 4\$160 réis. Além disso, despendeu $1 \$ 280$ réis das carretas que transportaram os caixotes ao porto de Pelotas, além de $1 \$ 900$ réis a um sujeito chamado Quincose, que Azevedo "lhe ficou a restar da compra que lhe fez das mencionados 50 caixões de velas", perfazendo tudo um total de 49\$740 réis. Lima nunca negou a dívida, mas não a tem pago e Azevedo assevera ser "pessoa que goza de crédito e bom conceito, e nas suas transações do comércio que exercita, nunca pediu pagamento de quantia alguma que

${ }^{22}$ Ofícios de 30.01.1836 e 04.03.1836 do Juiz de Paz de São José do Norte ao Presidente da Província Arquivo Histórico RS - Justiça - Correspondência, São José do Norte, Juízo de Paz, 1836-1843, maço 47. 
verdadeiramente se lhe não deva”. A sentença passada na Corte de Apelação deu ganho de causa a Azevedo, contra o apelante João Moreira Lima. ${ }^{23}$ Assim, o passageiro português João Moreira Lima aparece nesta ação como um indivíduo que tinha relações comerciais com o proprietário do patacho Dois Irmãos. Talvez esses dois portugueses - João Moreira Lima e Antônio Pereira de Azevedo - fossem sócios neste contrabando de pretos novos (e quem sabe mesmo em outros, bem sucedidos, e que portanto não deixaram pistas).

A sociedade escravista brasileira insistia em se perpetuar. A força da escravidão (Chalhoub 2012) naquelas primeiras décadas dos oitocentos imperial brasileiro permeava todas as instâncias e mentalidades sociais. A carência ou ineficácia dos próprios instrumentos de controle social imperial e a conivência entre o judiciário, a polícia, a sociedade branca e livre e os traficantes, tornava qualquer medida repressiva difícil e o seu resultado frustrante. Havia ainda as disputas das autoridades públicas locais e a indecisão das mesmas entre a ilegalidade escravista costumeira e os oscilantes ditames do governo imperial e de suas leis. Se os libertos sofriam com a precariedade estrutural da liberdade no Brasil escravista oitocentista (Chalhoub 2010), o caso dos africanos livres era ainda mais dramático, sendo suas estratégias de resistência muito mais frágeis (ainda mais quando recém chegados), por não conhecerem as culturas locais e possuírem poucos aliados, fora os seus malungos, que estavam em idêntica situação de fragilidade.

\section{Fontes}

Arquivo da Marinha (Rio de Janeiro) - Divisão de Acesso à Documentação / Diretoria do Patrimônio Histórico e Documentação da Marinha - Manoel Maria Ricalde Júnior.

Arquivo Histórico do Rio Grande do Sul. Hé pois percizo que todos partilhem as fadigas da guerra: Coleção Varela - Documentos sobre a Guerra Civil Farroupilha, 1835-1845. São Leopoldo - RS: Oikos Editora, 2019.

Arquivo Histórico do Rio Grande do Sul - Autoridades municipais - São José do Norte, Correspondência Expedida, 1832/1836, maço 248.

Arquivo Histórico do Rio Grande do Sul - Justiça - Processos - São José do Norte Juízo de Órfãos, 1833-1860, maços 45, 91, 97.

Arquivo Histórico do Rio Grande do Sul - Justiça - Correspondência, São José do Norte, Juízo de Paz, 1836-1843, maço 47.

\footnotetext{
23 Apelação por pagamento de transportes marítimos. Arquivo Nacional - Relação do Rio de Janeiro apelante: João Moreira de Lima, apelado: Antônio Pereira de Azevedo, 1837.
} 
Arquivo Histórico do Rio Grande do Sul - Avisos do Ministro da Justiça, B.1-107, 18361840.

Arquivo Histórico do Rio Grande do Sul - Legislação, Coleção das Leis e Decretos, falas, portarias, etc. do Império do Brasil. Tomo V, códice 46.

Arquivo Nacional - Rio de Janeiro - Relação do Rio de Janeiro - Apelado requer pagamento dos transportes marítimos que realizara sob encomenda do apelante - Localização: 84.0.ACI.05473 - Apelante: João Moreira de Lima, Apelado: Antônio Pereira de Azevedo, 1837, nº 886 - caixa 50.

Arquivo Nacional - Rio de Janeiro - Gabinete do Ministro - Maço IJ ${ }^{1} 847$ - Ofícios da Presidência da Província do RGS dirigidos ao Ministério dos Negócios da Justiça - 1837 a 1836.

Arquivo Nacional - Rio de Janeiro - Gabinete do Ministro - IJ1848 - Ofícios da Presidência da Província do RGS dirigidos ao Ministério dos Negócios da Justiça -1837 a 1841.

Arquivo Público do Estado do Rio Grande do Sul - Juízo Municipal de São José do Norte - Processo de contrabando, auto 26, caixa 791.

Arquivo Público do Estado do Rio Grande do Sul - Tribunal do Júri da Vila de São José do Norte, Comarca de Rio Grande, 1838, Autos crimes pela importação de africanos novos, $\mathrm{n}^{0}$ 10, Réus: José Maria Ribas e Antônio Pereira de Azevedo, autora: justiça.

Arquivo Público do Estado do Rio Grande do Sul - Tribunal do Júri da Vila de São José do Norte, 1838, Crime de responsabilidade, autor: o Promotor Público, réu: Francisco da Costa Pinto (Juiz Municipal da Vila de São José do Norte), 1838 São José do Norte, $\mathrm{n}^{0} 9$.

Arquivo Público do Estado do Rio Grande do Sul - Juízo Municipal, 1843, Autos de recurso em causa crime, Recorrente: o Promotor Público da Comarca, Recorrido: Juiz Municipal.

Arquivo Público do Estado do Rio Grande do Sul - $1^{\circ}$ Cartório Civil e Crime, Pelotas, 1877, inventário $\mathrm{n}^{\circ}$ 93, inventariado: José Maria Ribas, inventariante: Lucinda Maria Ribas.

Arquivo Público do Estado do Rio Grande do Sul - Juízo Municipal, São José do Norte, inventário $\mathrm{n}^{\mathrm{o}}$ 138, 1874, Inventariado: Tristão Xavier Braga, inventariante: Clara Leopoldina de Carvalho.

Arquivo Público do Estado do Rio Grande do Sul - Juízo Municipal, São José do Norte, Inventário $\mathrm{n}^{\mathrm{o}}$ 145, inventariado: Joaquim Pires de Almeida Lopes, Inventariante: Maria Luiza do Espirito Santo, 1883.

Arquivo Público do Estado do Rio Grande do Sul - $1^{\circ}$ Cartório Civil e Crime, Pelotas, 1877, inventário nº 94, inventariado: Manoel de Sá Araújo, inventariante: Maria Ludgera de Azevedo Sá.

Arquivo Público do Estado do Rio Grande do Sul - Juízo do Civil de POA, Processo judicial embargo, $\mathrm{n}^{\mathrm{o}}$ 2814, Embargante: Francisco Lopes Guimarães, embargado: Manoel Maria Ricalde Junior - 1848.

\section{Bibliografia:}


Acioli, G., Menz, M. Resgate e mercadorias: uma análise comparada do tráfico lusobrasileiro de escravos em Angola e na Costa da Mina (Século XVIII). Afro-Ásia. n. 37, 2008, pp. 43-73.

Al-Alam, Caiuá. A Negra Forca da Princesa: Polícia, Pena de morte e Correção em Pelotas. Dissertação (Mestrado em História). PPGH / UNISINOS, São Leopoldo, 2007.

Alencastro, L. F. O trato dos viventes. Formação do Brasil no Atlântico Sul. São Paulo: Companhia das Letras, 2000.

Andrews, George Reid. Negros en la Nación Blanca: Historia de los afro-uruguayos, 1830-2010. Montevidéu, Libreria Linardi y Risso, 2010.

Berute, Gabriel Santos. Dos escravos que partem para os portos do sul: características do tráfico negreiro do Rio Grande de São Pedro do Sul, c. 1790- c. 1825. Dissertação (Mestrado em História) PPGH / Universidade Federal do Rio Grande do Sul, Porto Alegre, 2006.

Rio Grande de São Pedro do Sul, c. 1790 - c; 1830: tráfico negreiro e conjunturas atlânticas. (1740-1777). XAVIER, Regina Célia Lima. Encontro Escravidão e Liberdade no Brasil Meridional. São Paulo, Alameda, 2012: p. 207/228.

Bethell, Leslie. A Abolição do comércio brasileiro de escravos. Brasília: Senado Federal/Conselho Editorial. 2002. Disponível no seguinte endereço: http://www2.senado.gov.br/bdsf/bitstream/id/1063/4/621762.pdf

Borucki, Alex; Chagas, Karla y Stalla, Natalia. Esclavitud y Trabajo. Un estudio sobre los afrodescendientes en la frontera uruguaya, 1835-1855. Montevideo, Pulmón Ediciones, 2004.

Borucki, Alex. The 'African Colonists' of Montevideo: New Light on the Illegal Slave Trade to Rio de Janeiro and the Rio de la Plata (1830-42). Slavery and Abolition. Vol. 30, No 3, September 2009, pp. 427-444.

Bpxer, Charles R. O império marítimo português 1415-1825. São Paulo: Companhia das Letras. 2002.

Maiztegui Casas, Lincoln R., Orientales. Una Historia Política Del Uruguay. Tomo 1. De los orígenes a 1865. $2^{\mathrm{a}}$ edição, Montevidéu, Planeta, 2010,

Chalhoub, Sidney. A força da escravidão: ilegalidade e costume no Brasil Oitocentista. São Paulo: Companhia das letras, 2012.

- Precariedade estrutural: o problema da liberdade no Brasil escravista (século XIX). Revista de História Social, n. 19, 2010.

Ferreira, R. Dinâmica do comércio intra-colonial. Geribitas, panos asiáticos e guerra no tráfico angolano de escravos (século XVIII), in FRAGOSO, João, BICALHO, M. F., Gouvêa, M. de F. (Orgs.). O antigo regime nos trópicos: a dinâmica imperial portuguesa (Séculos XVI - XVIII). Rio de Janeiro: Civilização Brasileira, 2001, pp. 339-378.

Ferreira, Roquinaldo Amaral. "Fazendas" em troca de escravos: circuitos de crédito nos sertões de Angola, 1830-186o. Estudos Afro-Asiáticos. n. 32, dez., 1997: 75-96.

Florentino, Manolo. Em costas negras. Uma história do tráfico de escravos entre a África e o Rio de Janeiro. São Paulo: Companhia das Letras, 1997. 
Flores, Moacyr. Contrabando de Escravos. Porto Alegre: Pradense, 2013.

Flory, Thomas. El juez de paz y el jurado en el Brasil imperial. México: Fondo de Cultura Económica, 1986.

Fortes, Amyr Borges; Wagner, João Baptista Santiago. História administrativa, judiciária e eclesiástica do Rio Grande do Sul. Porto Alegre: Globo, 1963.

Gutiérrez, Ester J. B. Negros, charqueadas e olarias: um estudo sobre o espaço pelotense. $2^{\text {a }}$ ed. Pelotas: Ed. Universitária/UFPEL, 2001.

Isola, Ema. La esclavitud en el Uruguay. Desde sus comienzos hasta su extinción (1743-1852). Publicacion de la Comision Nacional de Homenaje del sesquicentenario de los hechos historicos de 1825, 1975.

Klein, Herbert. $O$ Tráfico de escravos no Atlântico. Novas abordagens para as Américas. Ribeirão Preto, SP, FUNPEC editora, 2004.

Kuhn, Fabio. Clandestino e ilegal: o contrabando de escravos na Colônia do Sacramento (1740-1777). XAVIER, Regina Célia Lima. Encontro Escravidão e Liberdade no Brasil Meridional. São Paulo, Alameda, 2012: p. 179/205.

Kühn, Fábio \& Comissoli, Adriano. Administração na América portuguesa: a expansão das fronteiras meridionais do Império (1680-1808). Revista de Historia (USP), v. 169, p. 53-81, 2013

Lello Universal. Novo Dicionário-Enciclopédico Luso-Brasileiro. Vol. 1. Porto: Lello\& Irmão, s/d..

Lima, Rafael Peter de. Andrés Lamas e a atuação da Legação Oriental na Corte imperial brasileira: escravidão e relações internacionais (1847-1869). Tese (Doutorado em História). PPGH, Universidade Federal do Rio Grande do Sul, Porto Alegre, 2016.

Mamigonian, Beatriz G. Africanos Livre:a abolição do tráfico de escravos no Brasil. São Paulo: Companhia das Letras, 2017.

Oliveira, Vinicius Pereira. Sobre Águas Revoltas: cultura política maruja na cidade portuária de Rio Grande/RS (1835-1864). Tese (Doutorado em História). PPGH - UFRGS - Universidade Federal do Rio Grande do Sul, Porto Alegre, 2013.

Osório, Helen. O império português no sul da América: estancieiros, lavradores e comerciantes. Porto Alegre: Editora da UFRGS, 2007.

Pinto, Natália Garcia. A benção Compadre: experiências de parentesco, escravidão e liberdade em Pelotas, 1830/1850. Dissertação (Mestrado em história) - PPGH / Unisinos, São Leopoldo, 2012.

Barrios Pintos, Aníbal. Historias privadas de la esclavitud: um processo criminal em tempo de la Cisplatina. In: BARRAN, José Pedro; CAETANO, Gerardo; PORZECANSKI, Teresa. Historias de la Vida Privada em el Uruguay. Montevidéu, Ediciones Santillana, 1996, p. 173 - 195.

Rpdríguez, Jaime. De Costa a Costa. Escravos, marinheiros e intermediários do tráfico negreiro de Angola ao Rio de Janeiro (1780-1860). São Paulo, Companhia das Letras, 2010.

- O Infame Comércio: propostas e experiências no final do tráfico de africanos para o Brasil (1800-1850). Campinas: Unicamp, 2000. 
Rodríguez, José A. Victoria. Evolución Histórica de la policia uruguaya. Tomo 1. Montevidéu, Biblos, 2005, p. 259.

Scherer, Jovani de Souza. Experiências de busca pela liberdade. Alforria e comunidade africana (Rio Grande, século XIX). Dissertação (Mestrado em história) - PPGH / Uniisnos, São Leopoldo, 2008.

Soares, C. E. L.; Gomes, F.; Gomes, J. B. F. No Labirinto das Nações. Africanos e Identidades no Rio de Janeiro. Rio de Janeiro, Arquivo Nacional, 2005.

Souza, Susana Bleil de e PRADO, Fabrício. Brasileiros na fronteira uruguaia: economia e política no Século XIX. In: GRIJÓ, Luiz Alberto [et al]. Capítulos de História do Rio Grande do Sul. Porto Alegre: Editora da UFRGS, 2004.

Studer, Elena F. S. de. La trata de negros em el Rio de la Plata durante el siglo XVIII. Montevidéu, Libros de Hispanoamérica, 1984.

Thompson Flores, Mariana. Contrabando e Contrabandistas na Fronteira Oeste do Rio Grande do Sul (1851-1864). Dissertação (Mestrado em história) - PPGH / UFRGS, Porto Alegre, 2007.

Vargas, Jonas Moreira. Pelas Margens do Atlântico: Um estudo sobre elites locais e regionais no Brasil a partir das famílias proprietárias de charqueadas em Pelotas, Rio Grande do Sul (século XIX). Tese (Doutorado em História) - PPGH / UFRJ, Rio de Janeiro, 2013.

Zabiela, Eliane. A presença brasileira no Uruguai e os tratados de 1851 de comércio e navegação, de extradição e de limites. Dissertação (Mestrado em História) PPGH / UFRGS, Porto Alegre, 2002. 